DOI :

\title{
Intervention in Higher Education by Disruptive Innovations
}

\author{
Dr. S Sriranjani Mokshagundam, Ph.D
}

Professor of Management,Sri JagadguruBalagangadhara College of Management Studies (SJBCMS),

\begin{abstract}
The emphasis of this paper is on the use of "disruptive innovation" in higher education. Higher Education Institutions (HEIs) in India are attempting to improve the standard of teaching by using learning technologies. Technology is also playing a major role in mixed learning with immersive learning environments, but these systems are not widely used. With the help of appropriate technologies, HEls have the ability to embrace and provide quality education to students of all streams. The aim of the research is to better understand the nuances of technological technologies and new technology activity in Bengaluru's higher education system. Secondary data was gathered from a variety of databases, including e-resources, annual reports, and the UGC journal over a three-year cycle. UGC publications have achieved methodological consistency by endorsing technological engineering philosophies, with members defining connotations for innovations through their use of them, rather than in accordance with a designer's wishes. According to the research, transformative technologies would improve the standard of Bengaluru's higher education institutions. Disruptive technologies such as Artificial Intelligence, Big Data Analytics, Virtual Reality, Augmented Reality, and Robotics also have a lot of space for understanding. Instead, a limited set of tools is being applied to a wide variety of activities. In the world of higher education, both the teaching profession and students must be mindful of new technological technologies. HEl stakeholders should also understand and implement applicable and appropriate technology. The use of technology outside of HEls has implications for learning and teaching monitoring, as well as the role of HEls in quality improvement, as they are no longer the gatekeepers of information.
\end{abstract}

KE Y W O R D S: Disruptive Innovation, Higher Education, Technologies, Quality Improvement

\section{INTRODUCTION}

Joseph Schumpeter, the Nobel Prize Laureate in Economics, coined the term "innovation" in the 1930s. He sees creativity as a critical mechanism in industry and the economy. After analyzing a variety of literatures on innovation, Kotsemir et al. (2013: 12) came to the conclusion that innovation encompasses not only innovative and creative ideas, but also improvement and productivity in terms of market invasion and rapid marketing of new goods. Without a question, technological and engineering research underpins innovation, as well as other fields such as education, which includes innovative systems and methods of studying, teaching, and management.

Clayton Christensen coined the term "disruptive creativity" in 1995. Disruptive progress focuses on the 'technological heart.' The Internet is the perfect example of disruptive and progressive creativity. Christensen and Raynor (2003) agree, and Isenberg (1999) called the internet the "mother of all disruptions." The "Internet" was introduced into the world as a revolutionary breakthrough, and today a substantial portion of the global population is devoted to it and heavily reliant on it for day-to-day business operations.
In today's higher education system, a slew of transformative technologies are surfacing. Artificial intelligence, virtual reality, augmented reality, robotics, and immersive class rooms are all emerging innovations that are helping to improve the experience of higher education. As a result, information and communication technology (ICT) is rapidly evolving (ICT). ICT continues to be widely used in schooling and preparation, particularly at higher education institutions.

If cellular phones are disruptors, fixed line telephony is disrupted, and if community colleges are disruptors, three-year degree courses are disrupted, according to Christensen (2017). These principles of transformative innovation in ICT and higher education are explained. Clayton Christensen also wrote books focusing on his transformative innovation philosophy, such as Disrupting Class (for K-12 high schools) and The Future University. According to Christensen and Eyring (2011), combining low-cost, convenient online learning with occasional classroom-based teaching will improve university success without compromising the strict standards and consistency set by the approved entity. 


\section{Disruptions in Higher Education}

Disruptive technologies are upending India's traditional teaching and learning methods. Since they were born with electronics, students are now called millennials and tech-savvy. The digital medium has changed the way people learn. It is possible to learn in a more comfortable and easy manner. It can also be adaptable, spanning time and space, allowing for lifelong learning. Jay Cross invented the word "e-learning" or "digital learning." Computer-based learning and computer-based teaching (CBT) started in 1984, according to Cross (2004). As the internet was first widely used in the early 1990s, there were only a few words for new types of learning: multimedia learning, online learning, m-learning, hybrid learning, and deeper learning.

Furthermore, higher education cannot ignore the importance of gamification in the teaching and learning process. MonsoonSIM, for example, offers students with an experiential learning experience while simultaneously assisting in the transformation of education (MonsoonSIM, 2017). In total, about 2,000 (2000) students from different faculties at UTM benefited, with some students having no previous knowledge of business at all. Unconsciously, twelve topics in the fields of business, accounting and finance, and human resource management may be mastered by playing games.

From one view, radical and transformative creativity in higher education is in the form of providing and gaining skills, combining the concepts of heutagogy (self-directed learning facilitated by web 2.0), andragogy, and pedagogy in a harmonious manner. To ensure progress in blended learning that requires self-monitoring and self-management, self-directed learning (SDL) as an integral cornerstone of andragogy and heutagogy should be encouraged. Meanwhile, SDL, self-monitoring, and self-management can go beyond materialistic encouragement innate motivation and spiritual motivation - and be motivated by motivation and sustainable motivation. (Zulkifli et al., 2013).

From another perspective, progressive and revolutionary creativity in higher education encourages graduates to think like pioneers in order to instil innovation strategies that benefit the country and humanity. Higher education should not only use innovative and revolutionary learning technologies, but also be able to deliver young generations that would be able to build more radical and disruptive developments.
Global groundbreaking universities are ostensibly attempting to establish their own distinctive benchmarks in higher education. Stanford University, Massachusetts Institute of Technology (MIT), and Harvard University are the top three most groundbreaking universities in the world, according to Reuters. The sixth-ranked Korea Advanced Institute of Science and Technology (KAIST) University has been named Asia Pacific's most creative university. Meanwhile, Singapore's National University (NUS) is ranked first in Southeast Asia.

\section{Impending Disruptive Innovations in Higher Education}

Despite the fact that higher education has a reputation for being sluggish to evolve, it is undeniable how transformative developments have become and continue to be in recent years. The Internet of Things (IoT), virtual reality, and advances in online learning have transformed how colleges reach out to potential students, interact with existing students, and provide them with the tools they need.

To keep on the cutting side of Higher Education technologies, forward-thinking colleges must go through some "growing pains," as for any disruption. It is up to these organisations' IT leaders to investigate the benefits and drawbacks of adopting emerging technology so that they can direct decision-making processes before external forces push their hand.

The followings are the most impending disruptive technologies impacting on higher education in present days and would become more germane in the near future.

\section{Competency-based Education}

Competency-based education (CBE) is familiar with all students who begin a curriculum with a variety of talents and proficiencies, each displaying in their own unique manner. Academics and educators have had access to the technologies that allows them to quantify these disparities and create adaptive learning systems as a result. These initiatives aim to improve student participation and academic quality in Indian schools and colleges.

Learning can now be more self-paced and individual-focused thanks to advances in $\mathrm{CBE}$, making it more accessible and competitive. CBE technology allow a student's need for more time concentrating on a certain field to be clearly assessed. Pedagogy has been able to address the demands of students who do not follow the rigid expectations of a "traditional" student thanks to technological advancements. Expect this technology will continue to change people's perceptions of formal education. 


\section{The Internet of Things}

In higher education, the Internet of Things has opened up a whole new world of possibilities. Increased collaboration between smartphones and "everyday things" translates to better data monitoring and processing, as well as enhanced contact between students, professors, and institutions, mostly without saying something. IoT allows students to learn what, how, and where they choose while also assisting professors in creating a more flexible and linked learning environment.

Predictive analytics, with the assistance of IoT technology, will offer further insight into how students are performing in the classroom and on campus. Universities will be able to adapt to early signs of a "at-risk" student at the crucial moment before the student's success starts to suffer with the right facilities in place.

The potential of IoT in Higher Ed seems to be limited only by the imagination of those who introduce it.

\section{Virtual/Augmented Reality}

Higher Education has started to enter the world of what was once called science fiction thanks to virtual and augmented reality technology. Students who have access to virtual reality will immerse themselves in real-life learning environments that might either be too risky or impossible to witness. Health students, for example, may now execute complicated operations in virtual reality without endangering themselves or their virtual patient. Students learning history will now take interactive tours of the ancient cities they are researching.

These reality-altering devices, on the other hand, aren't all helpful pedagogical instruments. They almost always necessitate extensive planning and investment in the infrastructure required to sustain them. We may see augmented environments becoming an inevitable (if not required) feature in higher education as these devices become more effective and less costly.

\section{Artificial Intelligence}

Jill Watson, a Georgia Tech assistant professor, is a robot who answers students' questions and emails reminders. Though artificial intelligence isn't actually taking India by storm in terms of higher education, the capacity for disruption is clear from its increase in mainstream popularity. As IBM's Watson was able to play against human contestants on Jeopardy!, it captivated viewers. Siri and Cortana, intelligent digital assistants, demonstrate how helpful A.I. can be in day-to-day tasks.Consider getting an A.I. professor's assistant or an online learning programme that adapts to the individual needs of each student.
Artificial intelligence that evolves and develops as it assists in the learning process will have a huge impact on higher education, both online and off.

Although higher education is not as susceptible to disruption as other sectors, such advances have undeniably changed the way students read, professors teach, and universities run. Despite the fact that these disruptions are often difficult for institutions to manage, they are ultimately helpful to higher education as a whole.

\section{Collaboration Platforms}

Videos, seminars, and forums combine educational content in a variety of ways from various media. This makes studying more enjoyable as well as emotional. As a result, these networks are encouraging higher education institutions to collaborate. A increasing number of organizations are working together in areas such as technology, science, and common values. The university's departments and Colleges in Higher Education are in frequent contact, and the faculty's dean reviews workload shifts and assesses their effect, whilst the staff addresses workloads and notes any problems or variations.

Collaboration is important for students to benefit from transformative innovation. Around the same time, they must work together to foster local learning environments. In Higher Education, the internet is a fantastic facilitator of cooperation. The causal cause is the removal of regional barriers that prevent students and teachers from collaborating locally and internationally. The Department of Higher Education in Karnataka must introduce and introduce such a shared forum for both the teaching community and the student groups across the board.

\section{Conclusion}

Higher education must transition from traditional approaches to hybrid learning centred on new technologies. Disruptive progress will undoubtedly improve the standard of higher education. Eventually, disruptive creativity in undergraduate education can play an important role in attracting interested students, but the most enticing forecast is the addition of a "everlasting hybrid learning cohort." It will be a watershed moment in India's higher education sector. 


\section{REFERENCES}

1. Cross, J. (2004). 'The future of eLearning'. On the Horizon, 12(4): 151-157.

2. Cross, J. A., Cross, J., and Dublin, L. (2002). Implementing e-learning. Dublin: American Society for Training and Development. Christensen, C.M. (2017). 'Disruptive Innovation'. Retrieved from http://www.claytonchristensen.com/key-concepts/ on 12 August 2017.

3. Christensen, C.M. and Eyring, (2011). 'The Innovative University: Changing The DNA Of Higher Education'. Forum the future higher education. Retrieved from https://net.educause.edu/ir/library/pdf/ff1207s.pdf on 13 August 2017.

4. Conole, G., et al. (2008) 'Disruptive technologies', 'pedagogical innovation': what's new? Findings from an in-depth study of students' use and perception of technology', Computers and Education, vol. 50, pp. 511- 524.
5. Isabel Sagenmüller (2017), Disruptive Education Technologies Poised To Change Higher Learning, https://www.uplanner.com/blog/disruptive-education-technologies -poised-to-change-higher-learning.

6. Conole, G., et al. (2008) 'Disruptive technologies', 'pedagogical innovation': what's new? Findings from an in-depth study of students' use and perception of technology', Computers and Education, vol. 50, pp. 511-524

7. Selwyn, N. (2007) 'The use of computer technology in university learning and teaching: a critical perspective', Journal of Computer Assisted Learning, vol. 23, no. 2, pp. 83-94.

Citation: Dr. S SriranjaniMokshagundam, Ph.D., "Intervention in Higher Education by Disruptive Innovations". American Research Journal of Business and Management, Volume 7, Issue No. 1, 2021, pp. 1-4.

Copyright (ㄷ 2021 Dr. S SriranjaniMokshagundam, Ph.D, This is an open access article distributed under the Creative Commons Attribution License, which permits unrestricted use, distribution, and reproduction in any medium, provided the original work is properly cited. 